\title{
The Microstructure of Practice Activities Engaged by Elite Youth Soccer Players
}

\author{
Mohd Faridz Ahmad ${ }^{1,2}$, Jeffrey Fook Lee Low ${ }^{1, *}$, Ali Md Nadzalan ${ }^{1}$ \\ ${ }^{1}$ Faculty of Sports Science and Coaching, Universiti Pendidikan Sultan Idris, 35900 Tanjong Malim, Perak, Malaysia \\ ${ }^{2}$ Faculty of Sports Science and Recreation, Universiti Teknologi MARA, Cawangan Perlis, \\ Kampus Arau, 02600 Arau, Perlis, Malaysia
}

Received June 24, 2021; Revised September 4, 2021; Accepted October 17, 2021

\section{Cite This Paper in the following Citation Styles}

(a): [1] Mohd Faridz Ahmad, Jeffrey Fook Lee Low, Ali Md Nadzalan, "The Microstructure of Practice Activities Engaged by Elite Youth Soccer Players," International Journal of Human Movement and Sports Sciences, Vol. 9, No. 6, pp. 1306 - 1313, 2021. DOI: 10.13189/saj.2021.090626.

(b): Mohd Faridz Ahmad, Jeffrey Fook Lee Low, Ali Md Nadzalan (2021). The Microstructure of Practice Activities Engaged by Elite Youth Soccer Players. International Journal of Human Movement and Sports Sciences, 9(6), 1306 1313. DOI: 10.13189/saj.2021.090626.

Copyright $(2021$ by authors, all rights reserved. Authors agree that this article remains permanently open access under the terms of the Creative Commons Attribution License 4.0 International License

\begin{abstract}
The objective of this study was to examine the microstructure of practice engaged by elite youth soccer players and compare it to non-elite soccer players. A total of twenty four training sessions $(n=24)$ were recorded (with 3 days per week, $3 \mathrm{~d} /$ wk) over 8 weeks of pre-competitive season. The microstructure of practice activities was divided into two main types that are Training Form (TF) and Playing Form (PF). The sub-activities in the TF consist of technical and conditioning activities while PF consists of tactical, match-play and small-side games (SSG) activities. The result showed that elite youth soccer players spent $46.8 \%$ in training form activities $(46.8 \%)$ followed by playing form (34.7\%) and others (18.5\%) while non-elite players spent $45 \%$ in training form, followed by playing form $(36.6 \%)$ and others $(18.4 \%)$. No significant differences were found between the elite and non-elite groups. In summary, elite youth soccer players had spent time in practice activities begin from training form, followed by playing form and others during pre-competitive season. During pre-competitive phase, coaches seem to focus on activities to regenerate and improve the player's conditioning and technical skills since the nature of training for these types of practice activities that had been done in isolation or in small group session. Therefore, an investigation on the types of activities engaged between the different phases should be included in future research.
\end{abstract}

Keywords Microstructure of Practice Activities,
Training Form, Playing Form, Elite Youth Soccer Players

\section{Introduction}

In recent years, the development of understanding towards the science of skill learning and the most suitable types of practice activities and instructional behaviours in developing the elite athletes has been expanded [1]. In addition, the development of players especially in soccer can be considered as a very complex and composed process [2]. Due to that, the components that is the most necessary and important in developing an elite player is the role of coaches [3, 4]. Coaches' training philosophy tends to emphasize on "technical skills" to be mastered first and form as the basis for tactical gameplay [5]. Globally, soccer is not only regarded as a cultural phenomenon among the society which constitutes the purpose for leisure and entertainment, but it had also increased and extended to become more attractive as a professional career among the new talents, and some of them are interested due to the impressive financial rewards [6]. Apart from that, the identification and development of youth soccer players have been increasing tremendously over the last 10 years among elite soccer clubs [7]. Previous study by O'Connor, Larkin and Williams [8] had described the way in identifying the talented soccer players by directly focusing on the ability, 
capability and coaching skills of the coaches and talent scouting team in order to predict and identify the future sporting talent based on many criteria especially on athlete's current performance.

Therefore, throughout their sporting careers, athletes have gone through the different stages and phases in the developmental pathway towards expertise [9, 10, 11] including soccer. Over all, the talent identification programs are allied with the subjective evaluation of the players' potential from the coaches and scouting team that evaluate and select the potential players based on the criteria that primarily rely on the personal taste, current knowledge and past experience [12, 13]. Previously, coaches and the coaching staffs typically went through the talent detection and identification process, and due to that, their ability to identify the talented individuals and potential athletes should never be underrated because it was a very subjective process [2] that might be either include equality, bias or equity. An athlete's success is commonly referred to as the duration of practice hours that they had spent, including their training background [14]. Previous studies however claimed that in determining the future success, practice hours have become a bad predictor since they found no differences in accumulating the practice hours for both organized and non-organized, between elite and non-elite soccer players $[14,15]$. Having said that, training will work differently towards different individuals based on their ability and adaptation [16]. The activities used may form the teaching and learning environment [17, 18] which become the primary medium for the development of the player's technical and tactical skills where previous studies [19, 20, 21] had agreed that when designing the practice activity, the main consideration is the retention and transfer of learning and skills into the actual performance. Even though their influences will differ throughout the stages of sports and talent development [22], the guidance from them is beneficial to develop successful athletes [23] and it may also lead towards improvement of team performance in competitive contexts [24].

There are still debates on which types of activities that are commonly used by coaches during training session among elite performers. In continuity, the types of practice activities previously had been divided into two types that are Training Form (TF) and Playing Form (PF). $\mathrm{TF}$ is defined as the session of training concentrated on skill component [25] as well as practicing in small groups which is more focusing towards non-competitive session $[18,26]$. In addition, Low et al., [27] argued that engaging in training form activities may produce negative transfer of skill acquisition towards competition match play. On the contrary, PF are activities that replicate the demands of the game match-play. Skill acquisition researchers argued that PF can promote the development of technical and perceptual-cognitive skills specific to open skilled sports [26, 28]. Engaging in these activities can produce positive transfer of skill acquisition towards competition
[27]. In addition, the introduction of PF can be considered as new and needs further investigation and confirmation.

In fact, even though there was a clear justification regarding the types of practice activities, sub-activities had varied in several studies and its category were determined only when it is appropriate in their respective studies. Previous studies on soccer had determine those sub-activities differently. The sub-activities for TF had been categorised as fitness, technical and skills [18, 26, 29] while O'Connor, Larkin and Williams [25] categorised it as individual, paired and drills. For PF, a similar sub-category had been found on previous studies $[18,26$, 29] where they categorised it as small-sided games (SSG), conditioning games and phase of play while O'Connor, Larkin and Williams [25] determine it as small-sided activities and larger activities. In addition, previous study by O'Connor, Larkin and Williams [25] identified the activities that had been done during practice session other than Playing Form and Training Form as well as in their sub-categories such as refreshment, naming it as transition.

As agreed by Ford, Yates and Williams [26], the players had spent more time in TF activities (less relevant to soccer match performance) rather than $\mathrm{PF}$ activities (more relevant to soccer match performance). In line with that, a study by Low et al., [27] who had examined the types of practice activities among youth cricket players found that the players had engaged more time on TF activities, followed by PF and others during competitive season. In addition, similar finding was found from a study by Partington and Cushion [18] as they investigated the coaching behaviours of elite English youth soccer coaches in different practice settings and gained insight into the coaches' cognitive processes underpinning these behaviours with TF activities are more dominant compared to PF activities during the mid-season practice session. In contrast, previous study by Fuhre and Sather [29] indicated that both under 16 professional and non-professional soccer team had spent more time on PF activity rather than on TF activity whereas another study by O'Connor, Larkin and Williams [25] also found the similar findings with Fuhre and Sather [29] where youth soccer players had spent more time on PF, followed by TF and inactivity as they studied the changes on the type and duration of coach behaviours on youth soccer players. However, there were some limitations from previous study that had been addressed where resting time was not separated from the recording of activity type which may lead to a situation where the percentage and time spent in playing form activity is likely to be over-reported by Miller et al., [30]. Therefore, this study had improvised the limitation from the previous study by Miller et al., [30] by adding the activity that were excluded from TF and PF activities which is known as others. Therefore, this study intend to examine the microstructure of practice during training season that had been used towards elite youth 
soccer players in eight weeks training sessions and compare with non-elite youth soccer players.

\section{Materials and Methods}

Two soccer teams playing at different levels of competitions in Malaysia took part in this study. The teams were different in terms of their playing level and are known as elite and non-elite team. Elite team is defined as a team that represented the state which played in Malaysia President Cup 2019 while the non-elite team is identified as a team that represented a university that competed in Higher Education Institution soccer competition (IPT League 2019). The lead researcher recorded the training sessions that was led by coaches on both elite and non-elite youth soccer players during pre-competitive season either outdoor or indoor setting, depending on the venue. A total of 24 practice sessions were recorded in eight weeks of study duration, three days per week. The recordings used a video camera (Sony HDR-PJ440 Handycam Video Camera Camcorder with Built-in Projector, Malaysia) to record the sessions. In addition, this video camera was positioned at the middle of the training area with an approximate height range between $1.75-2.0 \mathrm{~m}$ from the ground level. Then, the video was transferred into a performance analysis software (Sports Video Analysis Software Longomatch by Fluendo) in order to observe and analyse the microstructure of training. The duration of each practice session and sub-activities were recorded for each practice session for both teams. This study has divided those activities into two main soccer-related activities called Training Form and Playing Form with the additional of others activities. The practice activities were defined in Table 1.

For reliability, the test-retest reliability was conducted in identifying the intra-rater and inter-rater reliability as to ensure the consistency of the assessment. In this study, intra-rater was defined as lead observer that had watched the same training sessions with 2 different time (a gap of one week) while inter-rater was referred to 2 observers who have watched the same training sessions. By following the procedure from Low, et.al [27], intra-rater reliability was tested when the lead observer had to watch the recording video from 3 different practice sessions on 2 different time, with a 1-week gap between that time in order to prevent memory bias [31] while for inter-rater reliability, 2 observers (coach and lead observer) had watched the recording video on their own from 3 randomly selected training. Then, the percentage of the agreement was calculated. The level of inter- and intra-rater agreement was calculated by using the equation proposed by van der Mars, [32].

\section{(Agreements) / (Agreements + Disagreements) x 100}

This study showed that the percentage for intra-observer agreement ranged between $99.5 \%$ to $100 \%$ while percentage for inter-observer agreement ranged between $91.4 \%$ to $100 \%$ where both conform to the level of agreement (85\% and above) based on the recommendation from previous studies $[32,33]$. The duration of each practice session was analysed by using descriptive statistics and a multivariate analysis of variance (MANOVA) between groups factor. In this study, since the practice sessions were varied in the time duration, it had been normalized by converting it into the percentage for each session duration that the players had spent in Playing Form, Training Form and others as well as in the sub-categories. To get the percentage, the time spent in the two main activities and in others were then being calculated by dividing the duration of time spend on each activity with the total duration of the session and then multiplying by 100 . For the sub-activities, the same method was been used. The level of significance value was set at $\mathrm{p}<0.05$.

Table 1. The Definition of Each Activity

\begin{tabular}{|c|c|}
\hline Activity & Definition \\
\hline \multirow[b]{2}{*}{ Training Form } & $\begin{array}{l}\text { Technical } \\
\text { The session of fundamental soccer-related specific skills training by using a ball such as passing, shooting and } \\
\text { dribbling. }\end{array}$ \\
\hline & $\begin{array}{l}\text { Conditioning } \\
\text { Training session that emphasizes on developing fitness components such as cardiovascular endurance that had } \\
\text { been done either on field or at the gymnasium without the existing of soccer ball that may include warm-up } \\
\text { and cool down session. }\end{array}$ \\
\hline \multirow{3}{*}{ Playing Form } & $\begin{array}{l}\text { Tactical } \\
\text { Training session which incorporates either playing with modification of pitch area or full side. The session is } \\
\text { paused at several times with the instruction by the coaches prior to correction to be made. }\end{array}$ \\
\hline & $\begin{array}{l}\text { SSG } \\
\text { The session is conducted by playing at the modification of pitch area which is smaller than actual soccer field, } \\
\text { had been played less than } 11 \text { players for each side and with the modification of playing rules. }\end{array}$ \\
\hline & $\begin{array}{l}\text { Match-Play } \\
\text { Playing a full side game with a multidirectional match-play towards goal. }\end{array}$ \\
\hline Other & $\begin{array}{l}\text { Others (transition) } \\
\text { The activities that may include transition between one session to another session, refreshment (drinking } \\
\text { water), team talk and others excluding sub-activities inside training form and playing form. }\end{array}$ \\
\hline
\end{tabular}




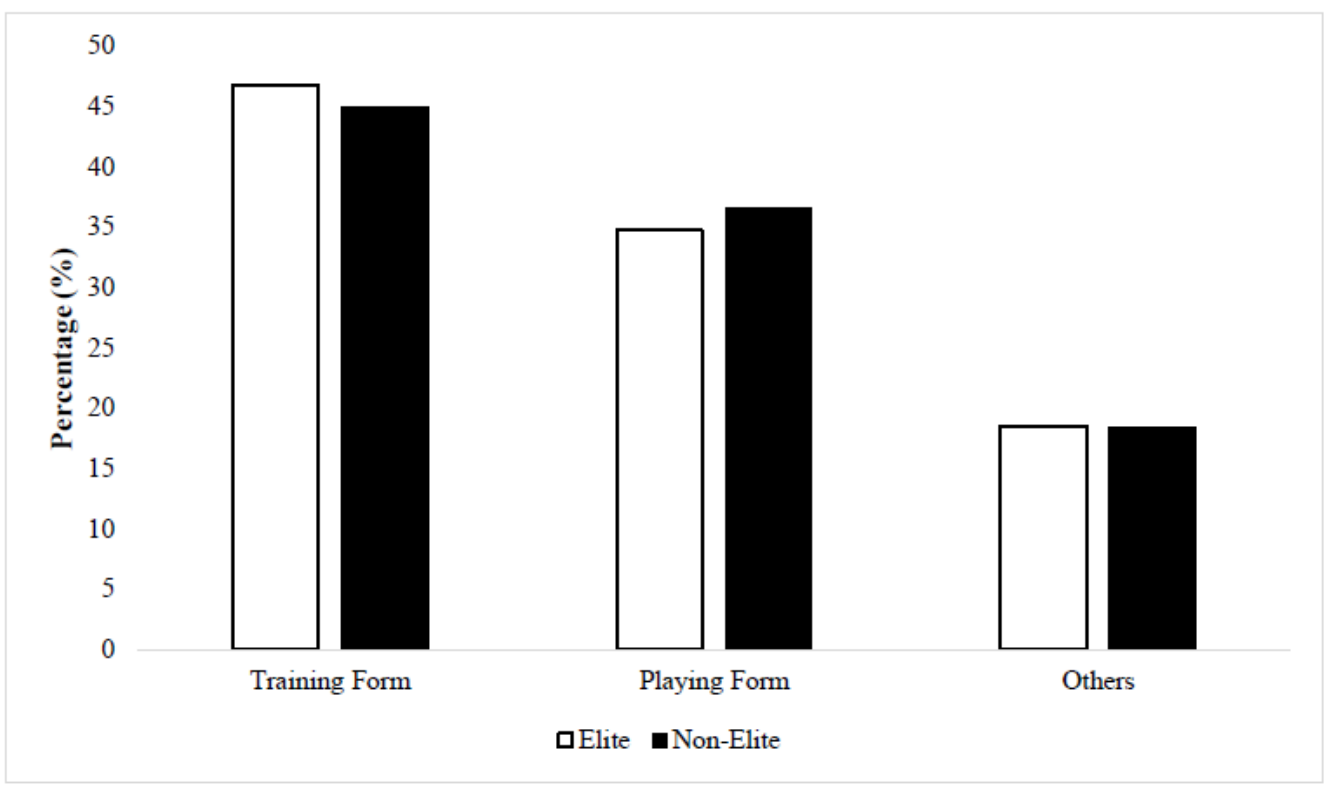

Figure 1. Percentage of microstructure of practice activities between groups for elite and non-elite soccer players

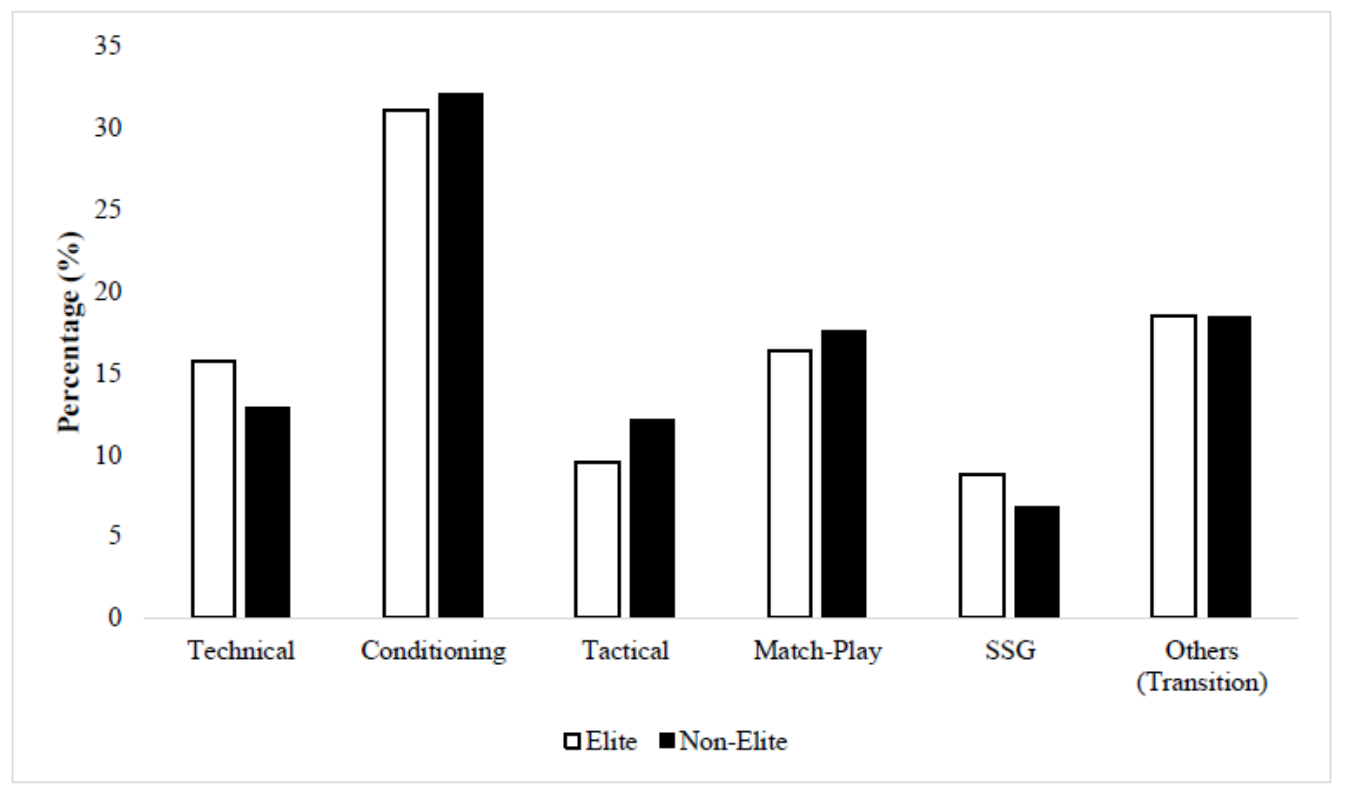

Figure 2. Percentage of sub-activities for elite and non-elite soccer players

\section{Results}

Figure 1 showed that elite players had spent $(46.8 \%)$ in training form activities followed by playing form (34.7\%) and others $(18.5 \%)$ while non-elite soccer players spent $45 \%$ on training form, followed by playing form $(36.6 \%)$ and others (18.4\%).

For the sub-activities categories, Figure 2 showed that elite players had spent $31.1 \%$ on conditioning activities, followed by others (transition) (18.5\%), match-play $(16.4 \%)$, technical activities (15.7\%), tactical activities $(9.5 \%)$ and lastly SSG $(8.8 \%)$. Then, for non-elite soccer players it showed that they had spent $32.1 \%$ on conditioning activities (32.1\%), followed by others (transition) (18.4\%), match-play (17.6\%), technical activities (12.9\%), tactical activities (12.2\%) and lastly SSG (6.8\%).

\begin{tabular}{ccccc} 
Table 2. & \multicolumn{4}{c}{ Significant Multivariate Effects $($ at $\mathrm{p}<.05$ level $)$} \\
\hline $\begin{array}{c}\text { Wilk's } \\
\text { Lambda }\end{array}$ & $\mathrm{F}$ & $\mathrm{df}$ & Error df & $p$ \\
\hline .980 & .293 & 3 & 44 & .83 \\
\hline
\end{tabular}

A one-way multivariate analysis of variance (MANOVA) was conducted to test the hypothesis and the result indicated that there was statistically no significant difference in microstructure of practice activities between elite and non-elite soccer players, $F(3,44)=.293, p>.05$; Wilk's Lambda $=.980$, partial eta squared $=.02$. This 
showed that both elite and non-elite soccer players were exposed with the similar practice types during their training session.

\section{Discussion}

The objective of this study was to examine the microstructure of training engaged by elite youth soccer players in eight weeks training sessions and compare it to non-elite. The finding of this study indicated elite soccer players had spent $46.8 \%$ in $\mathrm{TF}$ activities, then followed by PF (34.7\%) and others (18.5\%). The finding of this study was in line with previous study by Partington, Cushion and Harvey [34] who found that youth soccer players had spent more percentage in training form compared to playing form. Apart from that, study by Low, et al [27] also found the similar result where cricket players spent more percentage in training form activities, then later by playing form activities while the remaining percentage was spent on transition. Training form activities as suggested previously might have an advantage on the number of skill execution opportunities as it is significantly higher, resulting in more rapid short-term performance that could be acquired [35]. As found in this study, the factors that lead elite soccer players to spend more percentage was due to the training session that was conducted during pre-competitive season as it has also become a limitation of this study as the different phase of training might affect the activities during the training session.

During this phase, the possible explanation is that it might be due to the decision made by soccer coaches who decided to focus to the regeneration and improvement of the player's conditioning and technical skills since the nature of this types of practice activities that was conducted in isolation or in small group sessions. This are agreed in previous studies $[36,37]$ which stated that during the pre-competitive season, activities during training session are usually focused on re-establishing the players' fitness after the off-season period. In addition, Meckel et al., [38] also highlighted that the total volume and the number of training sessions during the pre-competitive season is more focused towards conditioning activities. Apart from that, other possible explanation might include the traditional focus on the introduction and improvement of skills and techniques which led to the higher amounts of training form activities As mentioned previously, in regards to individual and drills activities, both are technical oriented by its nature, which are directly linked to the motor skill development [39]. Due to that, this finding may be beneficial to coaches who wish to create a learning environment that reflects less-competition as this provides a benchmark for critical reflection upon the microstructure of their own practice. Therefore, this might become a reason on why elite soccer players spent more time on training form activities during pre-competitive period. The other factor involves the activities in the training program that was designed based from their experience rather than research. The possible explanation might be that each coach has their own way in designing a training program. The difference among coaches may include their own coaching philosophy, the variety in sources of knowledge as well as coaching experience that may contribute as one of the main factors that influences the training program. This was agreed previously by Williams and Hodges [1] who highlighted that when designing practice activities, coaches tend to rely on emulation of other coaches, their own intuition, and the traditions of the sport and club, rather than on evidence-based research findings.

In addition, when the practice activities had been compared to non-elite soccer players, this study found no significant difference in microstructure of practice activities after eight weeks of training session. The findings of this study is found to be contradicted with those reported by Deakin and Cobley [40] where after comparing between playing level, elite athletes showed to engage in greater amounts in activity that were more relevant to improve their performance compared to recreational athletes. Those the findings of this study indicated that microstructure of practice activities does not differ at different playing level and due to that, a conclusion can be made that both coaches deliver similar types of practice activities for their team respectively. In this study, it showed that elite and non-elite youth had spent time most in highest percentage type of activities which was training form, then followed by playing form and others. Interestingly, in sub-activities, the finding of this study showed that both elite and non-elite youth soccer players had spent the similar sequence practice at each sub-activities based on the percentage of time begin with conditioning activities, followed by others (transition), match-play, technical activities, tactical activities and lastly SSG. Due to this, it indicated that both coaches, even though coaching at different level of play, similar perception and idea on activities that they thought suitable to be included during the designing stage of training program. This might be the reason why there was no significant difference on microstructure practice activities between both groups. Even though no significant difference was found on the microstructure activities, the different on adapting the task may discriminate between playing level as claimed from previous study by Toering, Elferink-Gemser, Jordet and Visscher [41] who found that elite youth soccer players appear to reflect more on their previous actions for learning process and try very hard in order to execute their tasks successfully, and thus may benefit more from practice and competition, which could be one of the reasons as they play at a higher level.

In summary, the microstructure of practice activities of youth soccer players (elite and non-elite) had spent more on training form activities. Then, when compared between 
them, the results indicated that no significant difference was found. The finding of this study found to be in line with Ford, Yates and William [26] who suggested that engagement in activities that are focused on developing player skills via drills and isolation activities performed in a non-pressurized environment may exist across a number of sports. Although categorised as training form, drills and isolation activities provided greater player engagement with the ball and enables a high number of opportunities for technical skill execution [36]. However, Low et al., [27] highlighted that training form activities is predicted to have a negative transfer of skill acquisition to competition match-play. Therefore, when considering the training structure, the progression of training types towards playing form should be implemented. A study by Vickery et al., [42] suggested potential solutions to these problems by using more SSG in countering into positive transfer skill. As in high performance sports, it has been well documented that the maximum benefits are achieved when the training stimuli are deemed towards competitive demands [43], therefore further investigation on the effect of SSG training towards players' fitness components and technical abilities simultaneously were recommended.

\section{Conclusions}

In conclusion, the types of microstructure of practice activities engaged by elite youth soccer players were dominated by training form activities $(46.8 \%)$ followed by playing form $(34.7 \%)$ and others $(18.5 \%)$ while non-elite players also spent most of their time in training form $(45 \%)$, followed by playing form $(36.6 \%)$ and others $(18.4 \%)$ and resulting no significant different found between both groups. It showed that coaches who trained the different level of players tend to expose the players to the similar types of practice activities while being affected by the phase of training season. For sub-activities, both coaches preferred to emphasize the training types begin with conditioning activities, followed by others (transition), match-play, technical activities, tactical activities and lastly SSG. An investigation on the types of activities engaged between the different phases should be included in future research.

\section{Acknowledgements}

This study is extremely grateful to the soccer team management who allowed the training session to be recorded and also coaching staff and the players who were involved in the training. The authors would like to extend their gratitude to the Research Management and Innovation Centre of UPSI for sponsoring the publication of the study.

\section{REFERENCES}

[1] A. M. Williams, N. J. Hodges. Practice, instruction and skill acquisition in soccer: Challenging tradition. Journal of Sports Sciences, 23(6), $637-650,2005$. $10.1080 / 02640410400021328$.

[2] A. M. Williams, T, Reilly. Talent identification and development in soccer. Journal of Sports Sciences, 18(9), 657-667, 2000. https://doi.org/10.1080/02640410050120 041 .

[3] Cushion, C. Coaching and coach education. In A. M. Williams, B. Drust, M. A. Williams, P. Ford, Science \& soccer: Developing elite performers (3 ed., pp. 199-217), Routledge, United Kingdom, 2013.

[4] J. Stoszkowski, D. Collins. Sources, topics and use of knowledge by coaches. Journal of Sports Sciences, 34(9), 794-802, 2016. 10.1080/02640414.2015.1072279.

[5] S. Harvey, C. J. Cushion, A. N. Massa-Gonzalez. Learning a new method: Teaching games for understanding in the coaches' eyes. Physical Education \& Sport Pedagogy, 15(4), 361-382, 2010. 10.1080/17408980903535818.

[6] T. Reilly, J. Bangsbo, A. Franks. Anthropometric and physiological predispositions for elite soccer. International Journal of Sports Science, 18(9), 669-683, 2000. https://doi.org/10.1080/02640410050120050.

[7] S. Jones, B. Drust. Physiological and technical demands of $4 \mathrm{v} 4$ and $8 \times 8$ games in elite youth soccer players. Kinesiology, 39(2), 150-156, 2007. https://hrcak.srce.hr/ 21964.

[8] D. O'Connor, P. Larkin, A. M. Williams. Talent identification \& selection in elite youth football: An Australian context. European Journal of Sport Science, 1-8, 2016. https://doi.org/10.1080/17461391.2016.1151945

[9] B. S. Bloom, Developing talent in young people, Ballantine Books, USA, 1985.

[10] J. Côté. The Influence of the Family in the Development of Talent in Sport. The Sport Psychologist, 13, 395-417, 1999. https://doi.org/10.1123/tsp.13.4.395

[11] N. Stambulova. Athletes' crises: a developmental perspective. International Journal of Sport Psychology, 31, 584-601, 2000. urn:nbn:se:hh:diva-5908

[12] M. K. Christensen. "An eye for talent”: talent identification $\&$ the "practical sense" of top-level soccer coaches. Sociol Sport J. 26, 365-382, 2009.https://doi.org/10.1123/ssj.26 .3 .365

[13] C. Meylan, J. Cronin, J. Oliver, M. Hughes. Talent identification in soccer: the role of maturity status on physical, physiological \& technical characteristics. Int. J. Sports Sci. Coach, 5(4), 571-592, 2010. https://doi.org/10.1260\%2F1747-9541.5.4.571

[14] M. Hornig, F. Aust, A. Güllich. Practice \& play in the development German top-level professional soccer players. European Journal of Sport Science, 16, 96-105, 2016. https://doi.org/10.1080/17461391.2014.982204

[15] M. Haugaasen, G. Jordet. Developing football expertise: A football-specific research review. International Review of 
Sport \& Exercise Psychology, 5(2), 177-201, 2012. https://doi.org/10.1080/1750984X.2012.677951

[16] C. Bouchard, R. M. Malina, L. Pérusse. Genetics of fitness and physical performance, Human Kinetics, USA, 1997.

[17] P. R. Ford, J. Low, A. P. McRobert, A. M. Williams. Developmental activities that contribute to high or low performance by elite cricket batters when recognizing type of delivery from bowlers' advanced postural cues. Journal of Sport \& Exercise Psychology, 32, 638-654, 2010. https://doi.org/10.1123/jsep.32.5.638

[18] M. Partington, C. Cushion. An investigation of the practice activities and coaching behaviors of professional top-level youth soccer coaches. Scandinavian Journal of Medicine \& Science in Sports, 23 (3), 374-382, 2013. https://doi.org/10.1111/j.1600-0838.2011.01383.x

[19] C. J. Cushion, R. L. Jones. A systematic observation of professional top-level youth soccer coaches. Journal of Sport Behavior, 24(4), 354-376, 2001. https://www.cabdir ect.org/cabdirect/abstract/20013160603.

[20] L. Woodman. Coaching: A science, an art, an emerging profession. Sport Science Review, 2(2), 1-13, 1993. https://rl.talis.com/3/mmu/items/F13D4AD3-5D88-A635D3CA-319FECAC96B3.html.

[21] D. P. Broadbent, J. Causer, A. M. Williams, P. R. Ford. Perceptual-cognitive skill training \& its transfer to expert performance in the field: Future research directions. Eur J Sport Sci. 15(4): 322-331, 2015. https://doi.org/10.1080/ 17461391.2014 .957727$.

[22] J. H. Salmela, L. C. Moraes, Development of expertise: The role of coaching, families, and cultural contexts. In a J. L. Starkes, K. A. Ericsson (Eds.), Expert performance in sports: Advanced in research on sport expertise (pp. 275-294), Human Kinetics, USA, 2003.

[23] K. T. Koh, C. J. Mallet, C. K. J. Wang. Developmental pathways of Singapore's high performance basketball coaches. International Journal of Sport \& Exercise Psychology, 9(4), 338-353, 2011. https://doi.org/10.1080/1 612197X.2011.623466.

[24] C. H. Almeida, A. P. Ferreira, A. Volossovitch. Manipulating task constraints in small-sided soccer games: Performance analysis and practical implications. The Open Sports Sciences Journal, 5, 174-180, 2012. http://dx.doi.org/10.2174/1875399X01205010174.

[25] D. O'Connor, P. Larkin, A. M. Williams. Observations of youth football training: How do coaches structure training sessions for player development? Journal of Sports Sciences, 1-9. (2017a). https://doi.org/10.1080/02640414. 2016.1277034 .

[26] P. R. Ford, I. Yates, A. M. Williams. An analysis of practice activities and instructional behaviours used by youth soccer coaches during practice: Exploring the link between science \& application. Journal of Sports Sciences, 28(5), 483-495, 2010. https://doi.org/10.1080/02640410903582750.

[27] J. Low, A. M. Williams, A. P. McRobert, P. R. Ford. The microstructure of practice activities engaged in by elite $\&$ recreational youth cricket players. Journal of Sports Sciences 31(11), 1242-1250, 2013. https://doi.org/10.108 $0 / 02640414.2013 .778419$.
[28] A. M. Williams, P. R. Ford. Expertise \& expert performance in sport. International Review of Sport \& Exercise Psychology, 1(1), 4-18, 2008. https://doi.org/10.1 080/17509840701836867.

[29] J. Fuhre, S. A. Sæther. Skill acquisition in a professional and non-professional U16 football team: The use of playing form versus training form. Journal of Physical Education $\begin{array}{llll}\text { and } & \text { Sport, } 20 & \text { (3), 2030-2035, } 2020 .\end{array}$ 10.7752/jpes.2020.s3274.

[30] A. Miller, S. Harvey, D. Morley, R. Nemes, M. Janes, H. Eather. Exposing athletes to playing form activity: outcomes of a randomised control trial among community netball teams using a game-centred approach. Journal of Sports Sciences, 35(18), 1846-1857, 2017.https://doi.org/1 $0.1080 / 02640414.2016 .1240371$

[31] P. W. Darst, D. B. Zakrajsek, V. H. Mancini, Analysing physical education, Human Kinetics, USA, 1989.

[32] H. van der Mars. Systematic observation: An introduction. In P. W. Darst, D. B. Zakrajsek, V. H. Mancini (Eds.), Analysing physical education (2nd ed., pp. 3-19), Human Kinetics, USA, 1989.

[33] B. S. Rushall. Two observational schedules for sporting \& physical education environments. Canadian Journal of Applied Sports Sciences, 2, 15-21, 1977.

[34] M. Partington, C. Cushion, S. Harvey. An investigation of the effect of athletes' age on the coaching behaviours of professional top-level youth soccer coaches. Journal of Sports Sciences, 32(5), 403-414, 2014. https://doi.org/10.1 080/02640414.2013.835063.

[35] T. Gabbett, D. Jenkins B. Abernethy. Game-based training for improving skill and physical fitness in team sport athletes. International Journal of Sports Science \& Coaching, 4(2), 273-283, 2009. https://doi.org/10.1080/0 2640414.2016.1240371

[36] J. Bangsbo, M. Mohr, P. Krustrup. Physical \& metabolic demands of training \& match-play in the elite football player. Journal of Sports Sciences, 24, 665-674, 2006. https://doi.org/10.1080/02640410500482529.

[37] T. S. Jeong, T. Reilly, J. Morton, S. W. Bae, B. Drust. Quantification of the physiological loading of one week of "pre-season" \& one week of "in-season" training in professional soccer players. Journal of Sports Sciences, 29, 1161-1166, 2011. https://doi.org/10.1080/02640414.201 1.583671 .

[38] Y. Meckel, O. Doron, E. Eliakim, A. Eliakim. Seasonal Variations in Physical Fitness and Performance Indices of Elite Soccer Players. Sports, 6(14), 1-10, 2018. $10.3390 /$ sports 6010014

[39] J. F. Grehaigne, P. Godbout, D. Bouthier. The teaching and learning of decision-making in team sports. Quest, 53(1), 59-76, 2001.https://doi.org/10.1080/00336297.2001.104 91730 .

[40] J. M. Deakin, S. Cobley. A search for deliberate practice: An examination of the practice environments in figure skating and volleyball. In J. Starkes \& K. A. Ericsson (Eds.), Expert performance in sport: Recent advances, 2003.

[41] T. T. Toering, M. T. Elferink-Gemser, G. Jordet, C. 
Visscher. Self-regulation and performance level of elite and non-elite youth soccer players. Journal of Sports Sciences, 27, 1509-1517, 2009. https://doi.org/10.1080/026404109 03369919 .

[42] W. Vickery, B. Dascombe, R. Duffield, A. Kellett, M. Portus. The influence of field size, player number \& rule changes on the physiological responses \& movement demands of small-sided games for cricket training. Journal of Sports Sciences, 31(6), 629-638, 2013. https://doi.org/10.1080/02640414.2012.744080.

[43] T. Bompa, Theory and methodology of training: The key to athletic performance, Kendall/Hunt Publishing Company, USA, 1983. 